\title{
El fenómeno de la polisemia en la lexicografía actual: otra perspectiva*
}

\author{
PAZ BATTANER \\ Universitat Pompeu Fabra, IULA, grupo Infolex
}

\section{EL FENÓMENO DE LA POLISEMIA COMO UNIVERSAL LINGÜÍSTICO}

La multifuncionalidad de los signos lingüísticos, el que la misma forma léxica sirva para diferentes usos y reciba diferentes valores semántico-gramaticales, es un fenómeno del lenguaje natural que permite a los sistemas lingüísticos ser muy potentes y algo más económicos. Está ligado a las operaciones de comprensión y producción y apoyado, parece, en la capacidad de conexión múltiple de la mente humana. Fenómenos orales de homofonía (azar/azahar) y convenciones escritas de homografía $\left(\mathrm{real}^{1}, \mathrm{real}^{2}\right.$ y real $\left.{ }^{3}\right)$ contribuyen a complicar este fenómeno: un universal del lenguaje humano (Makkai 1972).

La multifuncionalidad se presenta en todos los componentes en que las lenguas pueden analizarse, pero se manifiesta específicamente en el componente léxico. El número tan elevado de unidades léxicas que las lenguas generan explica que este fenómeno sea más evidente en la descripción del léxico que no en la morfología o en la sintaxis. Precisamente uno de los nombres que recibe, el de homonimia, reconoce explícitamente el carácter 'designativo', uno de los caracteres propios del léxico.

Las manifestaciones extremas del fenómeno se han caracterizado grosso modo como homonimia o como polisemia, según se parta para su descripción de la fonética (en la homonimia dos secuencias coincidentes en la forma fonética no están relacionadas semántico-gramaticalmente) o del significado (en la polisemia se reconocen diferentes valores semántico-gramaticales bajo una misma forma fónica). Homonimia y polisemia son las dos caras extremas del mismo fenómeno, que aquí se enfocará desde la multifuncionalidad, tomando como punto de partida el valor semántico-gramatical de las unidades léxicas, es decir, se enfocará desde la polisemia. ${ }^{1}$

La lexicografía está implicada totalmente en este fenómeno lingüístico. Por lo demás no cabe distinguir en él entre lingüística teórica y lingüística aplicada; la descripción y el uso de recursos lingüísticos es una parte importante de la metodología de análisis de la lingüística teórica.

\section{EL TRATAMIENTO DADO A LA POLISEMIA Y LAS SOLUCIONES REFLEJADAS EN LA LEXICO- GRAFÍA DEL DÍA}

Los diccionarios, obras descriptivas del léxico de las lenguas por antonomasia, han resuelto y resuelven la manifestación de este fenómeno en el léxico de dos maneras: con el

* Este trabajo se inscribe en el Proyecto HUM2006-06982 «Las categorías verbo y adverbio en el DAELE». En él ejemplificamos con diccionarios de lengua española preferentemente, aunque el trabajo está enfocado hacia la Lexicografía general.

1 «No hallamos criterios fiables que nos permitan, en sincronía, diferenciar homonimia de polisemia» (Gutiérrez Ordóñez 1989: 126). Para el español, véanse los estudios de Muñoz Núñez (1999), Casas Gómez y Muñoz Núñez (1997). 
establecimiento de varias acepciones para una sola entrada polisémica; y con entradas independientes y diferentes artículos lexicográficos para diferentes formas homónimas. Bien en la macroestructura (entradas, lemas), bien en la microestructura (acepciones), la polisemia es una cuestión que hay que abordar, bien o mal, en cualquier labor lexicográfica. ${ }^{2}$

Organizar la presentación de un artículo polisémico en un diccionario requiere siempre a) enfrentarse a la selección y reconocimiento de matices semánticos y de variación gramatical en comprensión y en producción de formas fónicas coincidentes; b) advertir de las ambigüedades que se puedan producir en sus usos; c) marcar de alguna manera las diferentes relaciones morfológicas, sintácticas, también, fonéticas y pragmáticas que los usos de cada acepción diferenciada exigen. El fenómeno de la polisemia lexicográfica lleva adherido también el orden de las acepciones ofrecido en los diccionarios, muy especialmente las primeras acepciones y en general el de las acepciones generadoras de otras acepciones.

Hoy se pueden reconocer tres perspectivas para solucionar la polisemia lexicográfica: el modelo diacrónico, el modelo descriptivo sincrónico y el modelo generativo computacional. ${ }^{3}$

\section{1) Solución diacrónica}

En la tradición lexicográfica de gran parte del siglo Xx ha reinado todavía una explicación histórica para la cuestión de la polisemia en los diccionarios: la etimología y la consideración del orden de acepciones a partir del conocimiento de los textos antiguos, considerados también en sucesión histórica, daban una explicación implícita a esta cuestión. La visión diacrónica era generalmente satisfactoria o parecía satisfactoria. ${ }^{4} \mathrm{El}$ principio histórico para ordenar acepciones ha regido el tratamiento de la polisemia en la lexicografía española, en gran parte de la lexicografía romance y, naturalmente, en todos los diccionarios históricos.

Este principio, entre otras ventajas, también sirve para determinar el significado primordial (literal o recto), atribuido al lema. Se toma como punto de referencia la primera documentación en lengua vulgar. Si en esta documentación el significado se diferencia del del étimo (fuera éste latino, árabe, o de otra lengua), el cambio semántico es manifiesto y la definición de la primera acepción se muestra independiente; si el significado no difiere del del étimo en su lengua original, la continuidad es evidente y la definición es coincidente con la glosa del étimo. Esta coincidencia entre el significado del étimo y el significado de la primera documentación no ha sido siempre bien deslindada. ${ }^{5}$

Hay que recordar, como ejemplo bien elaborado y expuesto, el esfuerzo de Casares (1951: cap. III) por establecer, con este criterio diacrónico, la ordenación interna del artículo

2 Remitimos a la documentada obra de Porto Dapena (2002) para la bibliografía sobre la polisemia en la lexicografía tradicional (2002: 185, nota 4), a la que cabría añadir Vivanco Cervero (2003).

3 Porto Dapena (2002) señala tres soluciones dadas a la polisemia: el modelo diacrónico, el sincrónico y uno mixto, al que no concede validez.

4 Una excepción taxativa y consciente a esta solución se da en el orden de acepciones de voces que pueden ser adjetivos y sustantivos, muy concretamente cuando los adjetivos provienen de los sustantivos; la constatación de la moción de género en los diccionarios de lengua española hace que, en general, se antepongan las acepciones de adjetivo a las de sustantivo, v. majadero, - $a$ en $D R A E-1992, D E A$ y DRAE-2001.

5 El DRAE 2001 ha corregido muchos valores etimológicos en las definiciones de las primeras acepciones, lo que afectaba a la polisemia del lema. En algunas correcciones ha reintroducido ecos etimológicos como en la definición redactada en pasado de «judiada, 1. f. Acción mala, que tendenciosamente se consideraba propia de judíos.2. f. p. us. Muchedumbre o conjunto de judíos». 
de la voz orden en un proyecto de diccionario de base histórica. Con esta voz ejemplificaba Casares el problema de casos en que el étimo era ya polisémico en latín clásico y bajo latín $\mathrm{y}$, por tanto, la cuestión de su polisemia actual presentaba, desde la misma etimología, varias ramificaciones, lo que complicaba ejemplarmente la ordenación interna de sus múltiples acepciones en un posible artículo lexicográfico.

Desde la perspectiva diacrónica son dos las soluciones que se encuentran para exponer e integrar la polisemia de las unidades léxicas.

a) La exposición lineal de significados diferenciados se presenta a partir del significado primordial (literal), seguido en orden de documentación histórica de otros varios significados considerados a su vez primordiales e independientes; tras ellos vienen acepciones que reciben alguna marca: voces con sentido figurado, voces de especialidad y voces restringidas diatópicamente. Algunas voces fuertemente polisémicas ofrecen dos o tres acepciones que actúan como primordiales y cada una de ellas genera a su vez también otras acepciones, que llevan o no la marca de traslación semántica, representada tradicionalmente por la marca fig. Este es el método de la tradición lexicográfica del $D R A E$ hasta la edición de 1992 inclusive.

Este modo de exponer la polisemia hace que acepciones relacionadas semánticamente aparezcan distanciadas en la exposición lineal debido al orden de acepciones numeradas correlativamente en los artículos lexicográficos. Tómese por ejemplo cara, que presenta varias tandas de acepciones figuradas en el $D R A E-1992$ y que se ha reelaborado para la edición de $2001 .^{6}$

b) La exposición arbórea y jerárquica distingue acepciones y subacepciones y de esta manera soluciona este obstáculo en los diccionarios que resuelven el fenómeno de la polisemia desde el punto de vista diacrónico. Realmente no se pierde la solución del orden histórico, que deja resuelto el problema de la acepción primordial o senti-

6 «cara.. f. Parte anterior de la cabeza humana desde el principio de la frente hasta la punta de la barbilla. Se usa, por ext., para designar la de algunos animales. || 2. Semblante, expresión del rostro. José me recibió con buena CARA. || 3. V. encaje de la cara. || 4. Parte inferior o base del pan de azúcar. || 5. V. miel de caras. || 6. Fachada o frente de alguna cosa. || 7. Superficie de alguna cosa. Las CARAS de una moneda, de una lámina. || 8. Anverso de las monedas. || 9. fig. Presencia de alguien. Lo hizo en su CARA. Hay CARAS nuevas. I| 10. fig. Aspecto o apariencia de una cosa o asunto. El pastel, el negocio tienen buena CARA. || 11. fig. y fam. En ciertas expresiones, desfachatez, descaro. Fulano tiene mucha CARA. Se necesita CARA para hacer eso. II 12. fig. V. hombre de dos caras. || 13. Agr. Conjunto de entalladuras contiguas hechas en un árbol. [...]» (DRAE-1992).

En la última edición, las anteriores acepciones figuradas 9, 10 y 11 resultan las 8, 9 y 10 actuales no marcadas, cuyo orden no se sabe a qué responde; el artículo queda de la siguiente manera: «Parte anterior de la cabeza humana desde el principio de la frente hasta la punta de la barbilla. || 2. Parte anterior de la cabeza de algunos animales. || 3. semblante (|| representación de algún estado de ánimo en el rostro). José me recibió con buena cara. || 4. Parte inferior o base del pan de azúcar. || 5. Fachada o frente de algo. || 6. Superficie de algo. Las caras de una moneda, de una lámina. || 7. anverso (|| de las monedas). || 8. Presencia de alguien. Lo hizo en su cara. Hay caras nuevas. || 9. Aspecto o apariencia de una cosa o asunto. El pastel, el negocio tienen buena cara. || 10. coloq. desfachatez. Fulano tiene much cara. Se necesita cara para hacer eso. || 11. Agr. Conjunto de entalladuras contiguas hechas en un árbol. [...] (DRAE-2001).

Al mantener el orden y no consignar marca alguna, las acepciones 8, 9 y 10 del DRAE-2001 quedan descolocadas, pues no se relaciona la 1 con la 8 , la 3 con la 9 y las 5-6 con la 10. La solución con marca fig. tampoco lo relacionaba explícitamente, pero advertía; ahora no queda ninguna advertencia, el desorden de la polisemia se agrava y complica el artículo, aunque se haya introducido simplificación con remisiones a otras locuciones y se haya intentado dar información más precisa con la consignación de la acepción con que coincide la remisión. 
do literal; las definiciones relacionadas semánticamente con alguna otra acepción se presentan como subacepciones dentro de otra acepción principal, lo que ayuda a distinguir entre niveles y ramas de polisemia y por tanto entre acepciones de diferente jerarquía (acepciones y subacepciones). Todo ello ofrece un orden interno del artículo muy satisfactorio y soluciona las discusiones sobre polisemia semántica y contextualización del sentido. Este es el método seguido por los grandes diccionarios históricos, que responden al método de la lingüística diacrónica y que ciertos diccionarios monolingües generales han seguido, como el $D U E^{7}$.

2) Solución descriptiva y sincrónica

La perspectiva descriptiva y sincrónica de la lexicografía actual, reforzada por la atención de los lingüistas en resolver cuestiones de aplicación a la enseñanza, a la estandarización y normalización, etc. de las lenguas, se ha planteado también una solución para la polisemia en la descripción del léxico.

Los diccionarios que se consideran descriptivos de una sincronía y que trabajan con documentación, no parten de la etimología, dan por sentada la polisemia en la lengua, en el mismo nivel que los homónimos y homógrafos, ${ }^{8} \mathrm{y}$ hacen valer criterios semánticos y gramaticales exclusivamente para desdoblar lemas y entradas. Bajo esta concepción, se prescinde de etimología y quedan sin resolver los significados primordiales:

a) una primera solución es considerar homónimos los significados distantes de voces aunque hayan evolucionado semánticamente de forma independiente a partir del mismo étimo. Es decir, lo que venía siendo la solución tradicional para los homónimos con respecto a la diferente etimología (real ${ }^{1}$ real $^{2}$ y real ${ }^{3}$ ), se aplica al estadio de lengua descrito, pues la etimología no parece contar. Diccionarios que aportan esta solución son Lexis y, curiosamente, el $T L F$, para la lengua francesa ${ }^{9}$ para el español encontramos esta solución en el $D E A$, por

7 Tómese como ejemplo cara del DUE-1998 que incorpora los sentidos figurados en las diferentes acepciones:

3 («Poner. Tener»). *Gesto que denota un estado de ánimo: ‘Puso cara agria. Tenía cara de estar disgustado’ $\square$ *Aspecto de la cara que denota cierto estado de salud o cualquier otro estado físico: 'Ha traído buena cara del campo. Ha puesto mala cara cuando se lo he dicho. Tienes cara de no haber dormido'.

4 (fig.). *Aspecto o *apariencia. Manera de presentarse una cosa, por la cual produce cierta impresión: 'Sólo se preocupan de la cara. Ese pastel tiene muy buena cara'. $\square$ «Cariz». También, aplicado a cosas no materiales: 'No me gusta la cara que presenta el negocio'.

5 En un objeto laminar, cada una de sus dos *superficies: 'Cabría en una hoja de papel escrita por las dos caras'. (...) $\square$ En sentido restringido, y por oposición a «dorso» o «reverso», la que se considera principal de esas dos superficies. $\square$ En una *moneda, *medalla o *estampa, la superficie en que está representada una cara o figura humana o de animal, o la figura más representativa.

6 (*geometría). Cada uno de los planos que forman un ángulo diedro o sólido, o cada una de las superficies que Iimitan un poliedro. (...) $\square$ Cada plano de un *cristal mineral. $\square$ «*Lado». Superficie de las que limitan una cosa: 'La cara de arriba del cajón'. $\square$ *Fachada de un edificio o parte delantera de otra cosa: 'La cara del altar'.

(etc.)

8 Se ha rastreado indirectamente esta cuestión de tratamiento de la polisemia en la lexicografía pedagógica para el español en el artículo de Hoyos 1999-2000, que persigue el tratamiento de la marca fig en la lexicografía española sin cuestionarse el orden de acepciones al limitar la ejemplificación a un tipo de nombres muy homogéneos.

9 Casos de $D E U M$ como acción ${ }^{1}$, acción ${ }^{2}$, chino $^{1}$ y chino ${ }^{2}$. El Trésor de la Langue Française sigue también este criterio (TLF, pp. XXXI-XXXV). 
ejemplo en la voz orden ${ }^{1}$ y $\operatorname{orden}^{2}$, y en el DEUM, también la voz orden ${ }^{1}$ y $\operatorname{orden}^{2}$, y acción ${ }^{1}$ y acción ${ }^{2}$, chino ${ }^{1}$ y chino ${ }^{2}$ que presentan doble entrada sin tener doble etimología.

b) otra solución, totalmente inversa a la anterior, es la de algunos diccionarios de aprendizaje, especialmente los editados para la lengua inglesa, ${ }^{10}$ en los que se describen, bajo el mismo lema y en una única entrada, unidades homógrafas de étimo diferente, es decir, se aumentan los artículos lexicográficos polisémicos. La polisemia del artículo lexicográfico se complica, aunque la búsqueda de la entrada en el diccionario pueda resultar más fácil. Es la opción del COBUILD en sus diferentes ediciones y la de Clave para la lexicografía pedagógica del español. ${ }^{11}$

Con este cambio de orientación y con el olvido de la información etimológica la cuestión de la polisemia parece complicarse aún más. La nueva lexicografía opera también con otros criterios para dar una respuesta a esta cuestión y se dota del concepto de significado nuclear para la acepción primera. ${ }^{12}$ Las directrices de la ordenación de la polisemia en los diccionario actuales son las relaciones establecidas en el léxico mental o en datos documentados, juntamente con la noción de significado nuclear.

Los datos extraídos de los córpora suministran dos criterios para organizar el orden de acepciones de un artículo polisémico: la frecuencia y las diferencias morfológicas y sintácticas. ${ }^{13}$ La orientación psicolingüística de la semántica de base cognitiva, el tercero.

\section{a) por frecuencias}

Las frecuencias son invocadas como criterio en el orden de acepciones en algunos diccionarios que tienen establecido un corpus informatizado, del que se extraen. El criterio rígido de primar la frecuencia en un determinado corpus dificulta encontrar un orden interno del artículo, con lo que el artículo a menudo pierde coherencia interna o queda fuera de ese criterio. ${ }^{14}$ Las frecuencias, que sólo se puede establecer por corpus y por un corpus representativo, no facilitan el orden lógico o de relación semántica entre las acepciones en torno a un significado nuclear, que los hablantes establecen espontáneamente (Meer 2000, DeCesaris y Battaner 2005, Battaner y Torner 2007) y dificulta la redacción y la consulta del diccionario.

10 Tómese como ejemplo funk, funky o to defer según el cobuild y confróntese con el oed, que presenta dos entradas para cada lema.

11 La inclusión bajo un mismo lema de adjetivos y sustantivos en español ha adoptado esta solución, con algunas inconsistencias (Battaner y Lahuerta 2002).

12 Al recorrer este punto, la lexicografía va cambiando de terminología. La primera acepción puede ser considerada como sentido literal, recto, propio, primordial, nuclear. Aquí se mantendrá la denominación de primordial para la metodología diacrónica y nuclear para la metodología sincrónica.

13 Sinclair es taxativo a este respecto en la argumentación de su planta para el cobuild. Además de no distinguir por categorías gramaticales, el orden de acepciones responde a varios criterios: frecuencia, diferencias de significado ('independence of meaning') y concreción, esto último retrasa las cepciones figuradas que corresponden en gran número a significados sin referencia física o material. El significado nuclear, aunque no sea el de uso más frecuente, es por el que se empieza a describir (COBUILD: viii y xix).

14 El GDUEA, dirigido por Sánchez, manifiesta en sus preliminares esta opción. Sin embargo en muchos artículos no se sigue. Por ejemplo, rémora se califica de [1] , frecuencia baja, y se antepone la acepción de 'Pez marino...' a la "2 FIG Se dice de la persona o cosa que entorpece la marcha o avance de una acción determinada". Se altera el orden por frecuencias que en la introducción se anuncia como principio rector; los sinónimos y antónimos que se ofrecen son naturalmente para la acepción 2. Como en otros artículos de este diccionario, la ausencia de ejemplos de su corpus CUMBRE en las primeras acepciones pone de manifiesto que en el corpus hay presencia de acepciones segundas y no las hay de la primera acepción. 


\section{b) por diferencias sintácticas}

El criterio de las diferencias sintácticas es muy rentable para lenguas de morfología pobre. En la lexicografía de las lenguas románicas las terminaciones suelen marcar la categoría sintáctica de la voz; desvelan, generalmente, las diferencias de flexión y construcción y exigen lematización y entrada diferentes, lo que alivia la polisemia de muchos artículos. En estas lenguas conviene ir pues a análisis gramaticales más finos si se quiere aplicar este criterio para exponer la polisemia y determinar el orden de acepciones.

El criterio sintáctico, aunque para los sustantivos no sea hasta ahora tan decisivo, es un criterio útil mantenido de forma muy coherente, junto al criterio semántico, en la ordenación del artículo del $D E A \cdot{ }^{15}$ Este criterio coincide con el tradicional al utilizar marcas de categorías secundarias, como la transitividad o intransitividad de los verbos, y es el aplicado también de forma rigurosa en diccionarios de régimen.

\section{c) por criterios semántico-cognitivos}

Finalmente se está aplicando un criterio cognitivo de base cultural a algunos diccionarios en proyecto. Van der Meer (2000) propone una etimología sincrónica que coloca en la mente de los hablantes. En el diccionario de México, Lara (1997) parte del concepto cultural de estereotipo de Putnam (1975) para determinar la primera acepción, lo que confiere estructura a la ordenación de las otras acepciones. ${ }^{16}$ Lara ha ido dando cuenta de sus decisiones y las ha expuesto globalmente en Teoría del diccionario monolingüe (Lara 1997). Sigue a Putnam (1975) en el uso de estereotipo, noción convencional asociada a la palabra y que puede no corresponder a lo determinado y exacto bajo perspectivas históricas o científicas ('realismo interno'). El estereotipo es un concepto que intenta salvar los problemas epistemológicos de la validez para la intercomunicación del lenguaje humano. Los hablantes competentes conocen el significado estereotípico, aunque sea equivocado desde el punto de vista lógico-científico, y un diccionario de lengua se debe a la conformación de los estereotipos en cada cultura.

La teoría semántica de los prototipos ${ }^{17}$ no ha generado diccionarios. Posiblemente porque esta orientación, que tiene hoy presencia notable en la Semántica, centra su interés en el hablante individual y no en lo compartido por la comunidad lingüística. Coincide con la de Putnam en que el hablante se forja un modelo para establecer categorías conceptuales, que para Putnam es explicativo de la intercomunicación y que para Lakoff y Langacker es explicativo del funcionamiento cerebral.

Sólo estas últimas soluciones se plantean de partida cuál sea el significado nuclear. ${ }^{18}$ Los otros criterios no tienen en cuenta este concepto y la determinación y el orden de las diversas

15 Un ejemplo de $D E A$ en que se observa el orden de acepciones por sintaxis es el artículo de cara; en él se establecen cinco grandes apartados: I nombre, II locución prepositiva con remisión a un ojo de la cara, III locución verbal y fórmula oracional, IV locución adverbial, V locución prepositiva.

En el primer apartado se subdivide en A) femenino, B) masculino y femenino, C) masculino en un cara a cara, el cara o culo (juego).

16 En la Introducción del DEUM se lee «El sentido recto corresponde al significado que, a lo largo de la historia y hasta hoy, se ha fijado en primer lugar en la memoria de la comunidad lingüística» (18).

17 El último manual de Cruse utiliza esta teoría para explicar el significado léxico (Cruse 2000), lo que no era tan evidente en el primero (Cruse 1986).

18 Por ejemplo, la voz orden tiene una sola entrada y dos grupos de acepciones en el diccionario GDUEA, se presenta bajo dos homónimos en el $D E A$ y en el $D E U M$. Los significados primordiales de cada entrada corresponden a la acepción 1 del DRAE-1992 «Colocación de las cosas en el lugar que les corresponde» y a la acepción 18 «Man- 
acepciones, principalmente el de la primera acepción, queda implícito. De hecho en la mayoría de artículos lexicográficos la primera acepción coincide con la tradición española, pasada por el cedazo del $D U E$ - 1967, que ya distinguía entre primera acepción histórica, pero actual y viva en el momento de la redacción del diccionario, y otras primeras acepciones, históricas pero anticuadas, presentadas con letra cursiva de menor tamaño. ${ }^{19}$

\section{3) Solución a la polisemia en modelos computacionales}

Actualmente para salvar el escollo de la ambigüedad que genera la polisemia en el procesamiento de las lenguas por medios tecnológicos, la lexicografía ha descubierto otra orientación, que se está desarrollando en la lexicografía computacional, para ofrecer el fenómeno de la polisemia. En este enfoque la ambigüedad que generan en el uso, y por lo tanto la polisemia de las voces, se convierte en cuestión fundamental junto a la información sintáctica que cada empleo ofrece y cuyo conocimiento exacto y disponibilidad certera permitiría la selección léxica en las frases y en el discurso. ${ }^{20}$ La necesidad de salvar esta dificultad coincide en parte con la orientación lexicalista de la gramática, que busca la estructuración del léxico y multiplica las clases de palabras en busca de bloques o conjuntos semántico-sintácticos en que el vocabulario se pueda encuadrar. A lo que responde uno de los objetivos de Redes.

Algunos de los trabajos de esta orientación sobre la regularidad de la polisemia son los publicados en el entorno de Pustejovsky (Pustejovsky 1995, Pustejovsky y Boguraev 1996, Ravin y Leacock 2000), que estudian especialmente el valor predicativo de sustantivos, adjetivos y verbos, la exigencia de argumentos que las voces presentan y su relación con factores explicativos (qualia) y eventivos.

Pustejovsky se remonta a Apresjan (1973), que distingue dos tipos de ambigüedad polisémica: la contrastiva, en la que el significado de la voz se ofrece con dos valores sin ninguna relación (homonimia) y la polisemia complementaria, en la que se advierte variación en el significado, aunque la relación semántica entre los distinguidos no se pierde.

Esta polisemia complementaria se manifiesta bajo la misma categoría gramatical, como sería el caso de 'abertura' y 'objeto que cierra esa abertura' para acepciones de puerta, postigo o ventana, o el de 'institución' y 'edificio donde actúa esa institución’ para acepciones de banco, diputación, parlamento. ${ }^{21}$ Polisemia contrastiva sería el caso de diferencias fundamentales del

dato que se debe obedecer, observar y ejecutar» de ese mismo diccionario. En el GDUEA sólo se tiene en cuenta para la frecuencia la forma y por tanto la frecuencia no determina la acepción inicial; en el caso de orden se marca [5], lo que no tiene ninguna información para una voz con tan alta polisemia. En el $D E A$ la determinación de acepciones de esta voz se basa primero en relaciones semánticas con lo que las acepciones de orden como 'institución religiosa' se agrupan en el subconjunto B, 11 y 12 de orden ${ }^{1 ;}$ estas acepciones siguen a la correspondiente al sacramento de la Iglesia Católica, acepción que está incluida en el subconjunto A,9; el grado en el sacramento del orden se describe también en B 10; orden $^{2}$ parte de la acepción de 'mandato'. El diccionario de México también presenta una solución similar, aunque menos detallada.

19 DUE: «pedante $1 *$ Maestro que *enseñaba la gramática a los niños yendo a las casas.

2 (adj. y n. calif.). Se aplica a la persona que hace ostentación presuntuosa e inoportuna de sus conocimientos, así como a su tono, a sus palabras, etc.». Este mismo orden quedó alterado en el DRAE desde la edición de 1884.

20 Un recorrido del enfoque de la polisemia desde este punto de vista hasta 1991 en Kilgarriff (1992).

21 Todas las voces que en castellano indican 'dignidad' y muy frecuentemente 'territorio en que esa dignidad se ejerce' lo cumplen, así como 'tiempo en que esa dignidad se ejerce'. Voces como abadia, adelantamiento, almirantazgo, arcedianato, archiducado, arciprestazgo, arzobispado, por rastrear voces que empiezan con $a$, pueden ser un ejemplo de esta polisemia regular o lógica; ejemplo de 'dignidad' y 'tiempo acotado' serían papado, alcaldía, rectorado. 
significado (el citado anteriormente de las diferentes entradas de real, en diccionarios de la lengua española, o el repetido en inglés bank, 'ribera de río’y 'banco').

En la lexicografía española, ya María Moliner, en la Presentación de 1966, había escrito:

[...] se procura, en beneficio de la sobriedad y nitidez que se persiguen en el diccionario, prescindir de amplificaciones de significado que están en la naturaleza de la cosa o son de elemental sentido común; por ejemplo, no es necesario advertir en los nombres de recipientes que sirven para designar la cantidad del contenido que cabe en ellos, pues, si se consigna en algunos como sartén o caldera, habría que consignarlo con más razón en otros, ya que es evidente que se dice una olla de patatas, un cubo de agua, un plato de sopa, una cesta de manzanas, y habría, en realidad, que decirlo de todos los recipientes. Y de modo semejante, habría que consignar en el nombre de cada ciencia que se aplica también al libro que la contiene y a cada ejemplar de él: comprar una geografia (DUE-1967: XXIII; el subrayado es nuestro).

Vamos advirtiendo que hay cierta coincidencia entre los diccionarios convencionales y algunos de los modelos de tratamiento del léxico en la lingüística que tiene como objetivo el procesamiento de las lenguas. Se ha mencionado también que la distinción entre polisemia complementaria y polisemia contrastiva se ha empleado en diccionarios como Lexis, el TLF, DEUM y $D E A$ para determinar entradas, es decir, para establecer la macroestructura de los diccionarios.

En la teoría se avanza; en Lexicografía las propuestas más sobresalientes serían: el rechazo de las acepciones semánticas (sentidos que fragmentan y aíslan la unidad léxica de sus matices de significado y que llevan a la numeración de unidades léxicas homónimas) y la integración de algunas de sus diferentes actualizaciones de sentido (las tradicionales acepciones de 'sentido común' de María Moliner) en una matriz que configura globalmente la unidad léxica (Pustejovsky 1995: cap. 5). El procesamiento del lenguaje por medios tecnológicos no ha alcanzado, por el momento, el sentido común que María Moliner otorgaba a los usuarios de diccionarios y el procesamiento del lenguaje natural tiene que proporcionar a los programas informáticos, mecanismos de decisión ante la ambigüedad, sea esta muy alejada (polisemia contrastiva) o cercana (polisemia lógica).

\section{NuEVAS EXIGENCIAS DE REPRESENTACIÓN DE LA POLISEMIA EN LA LEXICOGRAFÍA ACTUAL}

El planteamiento más simple del tratamiento del léxico en la lingüística generativa, como en la aplicación computacional, fue el modelo enumerativo de lexicón ${ }^{22}$ con el que se han resuelto los homónimos y los artículos polisémicos en la lexicografía tradicional, es decir, con diferentes entradas y diferentes acepciones numeradas correlativamente; es la aplicación extensiva del ejemplo aquí citado de real. Las acepciones se tratan como unidades independientes; es decir, todo como homonimia contrastiva. Este modelo es poco elegante al tener necesidad de numerar los diferentes sentidos actualizables de una unidad para distinguirlos; en él la voz polisémica pierde su unidad, representada en el lema, y da origen a $n$ unidades, que complican el tratamiento léxico.

Una segunda versión avanzada del modelo enumerativo evita todo lo que se pueda la homonimia; la voz polisémica se concibe como una unidad a la que se atribuyen diferentes acepciones y 
matices y en la que la polisemia lógica aparecería marcada como subíndice de la polisemia contrastiva, en un modelo en cascada (plug in) (Pustejovsky 1995: cap. 3). En la lexicografía convencional este modelo correspondería a los diccionarios que diferencian lemas y entradas homónimas por sus diferencias semánticas y que organizan el artículo polisémico en acepciones y subacepciones, como se hizo en $D U E$, en cierta medida se hace en $D E A$ y en todos los diccionario históricos.

Pero el modelo enumerativo, en una u otra de sus versiones, no deja de multiplicar las unidades léxicas y -un paso más en la búsqueda del golem- no resuelve tampoco el uso creativo de las palabras; resuelve sí la polisemia contrastiva y la complementaria lógica, ${ }^{23}$ pero no resuelve la potencia creativa polisémica que, los diccionarios intentan resolver en su pura virtualidad y no en el uso real (los contextos), que, como todo el vocabulario, está sometido a una aparente idiosincrasia y que en los diccionarios monolingües tradicionales se apoya explícitamente en la competencia de sus usuarios, a los que la ‘comprensión' e ‘interpretación' adecuadas se les supone.

Para salvar esta dificultad, la lingüística computacional en su formulación de léxico generativo tiene un planteamiento más ambicioso. La voz polisémica se representa en ella como una unidad matriz que, en su actualización, sea capaz de:

a) diferenciar los matices semánticos que una misma forma ofrece como en una especie de tornasol y permitir la selección del matiz apropiado;

b) actualizar las diferentes posibilidades sintácticas para que la voz descrita pueda adaptarse y fusionarse sintácticamente con otras unidades; y, objetivo definitivo,

c) permitir el uso creativo de las palabras, es decir, atender tanto a usos conocidos por documentados como a usos nuevos posibles aunque, y esta es la novedad, no se tengan documentados.

El modelo que atienda a estos tres principios será un modelo generativo del léxico (Pustejovsky 1995: cap 5).

Podríamos decir también que estos objetivos han sido y son una meta ideal de toda labor lexicográfica, como lo muestran las diferentes soluciones que ofrece la historia de la lexicografía y que en la cita de María Moliner se esconden bajo el sentido común, tan difícil de definir y de modelizar. ${ }^{24}$ Efectivamente el significado de las voces es fluido, se inclina a un sentido y a otro, se traspasa, se cuela por las rendijas que el contexto ofrece. Esta permeabilidad no solo dificulta los objetivos de la lingüística computacional sino hace difícil e insatisfactoria la descripción semántica, asunto central de la labor lexicográfica. ${ }^{25}$

Ejemplos patentes de esta dificultad son casos en que los diccionarios consignan dos posibilidades semánticas dentro de una misma acepción, sin siquiera recurrir a varias acep-

23 Esta queda resuelta precisamente en la opción radical del $D E A$, que separa las entradas numerando correlativamente un mismo lema cuando son casos claros de polisemia contrastiva; distribuye en acepciones y subacepciones lo que podría ser polisemia lógica y marca con grupos encabezados por números romanos las diferentes categorías gramaticales que una misma entrada presenta o, cuando esto no basta, con capitales en negrita. Además numera correlativamente a lo largo del artículo las acepciones, no las subacepciones.

24 Un esfuerzo por definir el sentido común se encuentra en el filósofo que proporciona el concepto de aitiae o qualia como capacidad 'explicativa' de las unidades léxicas (Moravscik 1990, cap. V).

25 Los poetas han sido adelantados en señalar la insuficiencia de las lenguas para lograr descripciones semánticas satisfactorias de sus propias unidades. Bécquer, entre los poetas en lengua española, se queja «domando del hombre el pobre, mezquino idioma» (Rima I), repetidamente, de esta insuficiencia: «¡Lástima que el amor un diccionario/ no tenga, donde hallar/ cuándo el orgullo es simplemente orgullo/ y cuándo es vanidad!» (Rima XXXIII), pues bajo orgullo hay un uso, actualización, matiz, sentido, acepción, de vanidad. 
ciones. En la tradición española ocurre, entre otras fórmulas, en las soluciones 'acción y efecto' o 'calidad y cualidad', definiciones que dejan insatisfechos a usuarios y a lexicógrafos, pero que tienen su razón de ser; también en definiciones dobles, como las primeras acepciones de descuidar, despegar, ${ }^{26} \mathrm{o}$ en las que encaran un proceso en diferentes fases de su desarrollo (estructura eventiva) como desvelar ${ }^{1}{ }^{27}$ Otro aspecto de esta dificultad es el establecimiento de la hiperonimia-hiponimia y su consiguiente orden de aparición en algunos casos de confluencia en la extensión entre voces, como se pone de manifiesto entre $D R A E$ 1992 y $D R A E-2001$ :

macuto. m. Mochila de soldado. || 2. Por ext., cualquier tipo de mochila. (DRAE-1992, s. v.)

macuto. m. Mochila, especialmente la del soldado. (DRAE-2001, s. v.)

Cuál sea la primera acepción y su definición es el meollo de la polisemia; de manera que los diccionarios han venido ofreciendo definiciones múltiples, cambios entre una edición y otra, en su búsqueda de permeabilidad del significado nuclear de las voces.

Hay que tener presente que ofrecer fluidez del significado léxico, junto a otros matices que ha ido estudiando la sintaxis y que ahora se traspasan a los diccionarios (contabilidad, factividad, reciprocidad, posibilidad de tener complementos con cláusulas asertivas o interrogativas, etc.), puede dificultar extraordinariamente no sólo un modelo computacional, sino complicar extraordinariamente un diccionario convencional. ${ }^{28}$

La propuesta del léxico generativo reta a conseguir que un artículo lexicográfico permita a) fijar el significado nuclear o los nucleares de un lema, b) orientar sus condiciones sintácticas en cualquier contexto, y c) permitir que se pueda interpretar bajo varios sentidos en un corpus «extenso y abierto», ${ }^{29}$ todo ello sin ofrecer el orden de los modelos enumerativos. De esta manera el modelo generativo de léxico se acercaría a la competencia de un hablante cultivado; competencia que, como ya se ha recordado, también un diccionario general intenta describir.

Se requieren estos tres objetivos del modelo léxico generativo para que una teoría encare la polisemia en las lenguas de manera que no sobregenere la producción de expresiones semánticamente insatisfactorias y que resuelva las soluciones nuevas y creativas de que son capaces los hablantes. Es decir, lo que Coseriu delimitaba como norma frente a sistema, pero ofreciendo mayores y abiertas posibilidades (Coseriu 1978).

Hay que recordar que la propuesta de Pustejovsky, que venimos resumiendo (1995), se circunscribe a la polisemia que él llama lógica o complementaria, bajo un tratamiento formal de las lenguas; aunque es verdad que hoy se está proyectando a la descripción del léxico en

26 «descuidar. tr. No cuidar de alguien o de algo, o no atenderlo con la diligencia debida.» (DRAE-2001, s. v.); «despegar. [...] 5. prnl. Dicho de una cosa: Caer mal, desdecir, no corresponder con otra.» (DRAE-2001, s. v.).

27 «desvelar ${ }^{1}$, tr. Quitar, impedir el sueño, no dejar dormir. U. t. c. prnl. » (DRAE-2001, s. v.)

28 La segunda columna del COBUILD se ofrece como una posibilidad informativa para pocos usuarios, y de hecho, pocos estudiantes sacan partido de ella; en otros diccionarios la información sintáctica introducida conjuntamente con la definición dificulta la lectura de la definición, como por ejemplo el buen análisis sintáctico que se superpone a la definición de ligar $\mathbf{1 b}$ «Atar o sujetar [una pers. $(c d)$ a otra o a una cosa (comp A $o$ CON)] con lazos o trabas morales o legales. Frec el cd es refl. Tb sin compl.» (DEA, s. v.).

29 «given an open corpus of usage» es la expresión de Pustejovsky, lo que cambia el concepto de corpus como conjunto cerrado de datos lingüísticos (Pustejovsky 1995: 46). 
general. Se podría decir que, actualmente, tenemos una exigencia de representación (no ya sólo de descripción) del léxico.

\section{CONCEPTOS OPERATIVOS: SigNifiCADO NUCLEAR, EXTENSIÓN E INTENSIÓN, CAMBIO DE DOMINIO}

Llegados a este punto de la cuestión de la polisemia léxica y su tratamiento en los diccionarios, se puede plantear la viabilidad de transponer en cierta manera el concepto de léxico generativo a los diccionarios convencionales; es decir, adaptar el concepto de significado primordial al de nuclear, enriqueciéndolo con algunos de los desarrollos contemplados en la polisemia regular y otras aportaciones teóricas, lo que representaría reflejar en el diccionario las posibilidades semánticas contempladas en el léxico generativo.

La solución de prescindir del concepto significado primordial y concebir para cada voz una matriz semántica y explicativa desde la que se pudieran generar diferentes actualizaciones (muchas acepciones, si no todas), sin preeminencia en el orden, sino en función de relaciones sintáctico-contextuales, se ha pensado para las necesidades del PLN. En este supuesto ni la filogenia, que determina un orden cronológico de valores semánticos, ni la ontogenia lingüística, que puede determinar su orden de adquisición por los hablantes, son determinantes, pues vuelven en parte al modelo enumerativo del léxico. Tampoco la lexicografía convencional puede prescindir radicalmente ni de las coordenadas históricas en que el diccionario se proyecte ni de la documentación que represente la competencia de sus usuarios.

Una segunda opción es la que intentamos aquí aprovechar.

Es imposible hacer desaparecer el orden lineal en el texto escrito de un diccionario convencional, por la dimensión temporal de las lenguas, escritas u orales, aunque hoy la informatización permita ignorar y saltar en algunas circunstancias este orden. El mantenimiento de una acepción, que se pueda identificar con el significado nuclear, implica su determinación y el orden en que se presenten las otras posibles acepciones (actualizaciones del significado en función de los contextos).

El significado nuclear parece ser la piedra angular. Este podría ser determinado por el trabajo de lexicógrafos sobre encuestas entre los hablantes o por coincidencias entre las soluciones de la lexicografía convencional; ${ }^{30}$ a partir de él se ordenaría el artículo lexicográfico semánticamente, pensando en su mejor comprensión por parte del usuario, lo que sería cercano a una lógica natural fundamentada en la ontología cultural predominante en la lengua que el diccionario intente describir ${ }^{31}$. Hay algunos intentos en este sentido, como ya se ha dicho, pero son de difícil implementación para las decenas de miles de unidades que se han de describir.

Otra manera de plantearse este significado nuclear podría partir de lo que propone, teóricamente y sin formalismos, el filósofo Moravcsik (1990 y 2001). Para este filósofo del lengua-

30 Determinarlo entre los hablantes representaría estudiar, en parte, un aspecto de la ontogenia lingüística. Determinarlo en los diccionarios sería más arriesgado al ser obras en que la tradición tiene mucho peso; aunque estudios sobre la imagen cultural que reflejan los diccionarios (Evens, ed.1991) se acercan a estos intereses.

31 Cuestionándose también la noción de sentido nuclear o primordial y teniendo en cuenta la capacidad creativa de los hablantes, se lee en la 'Introducción' del DEUM: «En otras palabras, este Diccionario no hace distinción entre sentido recto o propio y sentido figurado, porque estas designaciones conllevan una actitud logicista de la lengua que no parece justificarse a la luz del pensamiento lingüístico moderno.» (18). 
je resulta útil aplicar los conceptos de intensión y de extensión ${ }^{32}$ de la filosofía a la semántica léxica. Toda unidad léxica tiene una faceta designativa, su extensión, y una faceta explicativa que aporta razonamiento explicativo, su intensión. Estos conceptos permiten a Moravcsik distinguir entre 'saber una palabra' y 'entender una palabra o generar su extensión'.

'Saber (el significado de) una palabra' es conocer la extensión o las extensiones socializadas de una voz, responde a la necesidad que tenemos de una palabra cuando se pregunta o se responde por el nombre de un referente manifiesto «¿cómo se llama esto?, ¿cómo se dice hacer así?, ¿cómo se dice de algo que es así?», y este referente puede ser el de una entidad, el de una acción verbal, o el de una propiedad. Las extensiones manifiestan la función designativa de las unidades léxicas y se necesitan taxativamente cuando se pregunta cómo se llama o dice algo. Los hablantes satisfacen siempre que pueden esta necesidad a los extranjeros que aprenden su lengua. Los diccionarios bilingües han intentado siempre contestar estas posibles preguntas que apuntan a la extensión socializada de la unidad léxica, lo que se llama también su capacidad convencional de referencia.

'Entender (el significado de) una palabra' es tener interiorizada una representación de sus condiciones de uso, la intensión, en virtud de la cual algo puede recaer en la extensión de esa palabra, aunque esta extensión no esté socializada, es decir, no sea 'corriente' llamarlo o decirlo así. En estos casos cuenta la potencia predicativa de las unidades léxicas (que también indica la designación puntual) y ciertas 'propiedades' que explican, que dan razón de este uso y que quedan manifiestas o puestas en relieve en el discurso en que las voces se actualizan. La intensión se divisa de forma aislada cuando se pregunta algo de una palabra que 'se sabe', «¿Qué quiere decir aquí esta palabra?, ¿cómo entiendes aquí esta palabra?». Los diccionarios monolingües incorporan implícitamente a sus objetivos responder a cuestiones como esta, no solo 'llamar', sino 'querer decir', dando a las unidades léxicas un sentido capaz de explicar muchas expresiones. Los significados se conciben como condiciones para aplicar patrones explicativos con los que se puede mostrar por qué y cómo algunas entidades materiales, eventuales, abstractas o transcategoriales están incluidas en la extensión de una unidad léxica dada.

Para Moravcsik la intensión es «el conjunto de condiciones explicativas necesarias, dadas en términos cualitativos» de las palabras, condiciones que se manifiestan por la capacidad predicativa (explicativa, desde el punto de vista de Moravcsik, que concibe el género humano como homo explanans) de todas las voces descriptivas, es decir, sustantivos, adjetivos, verbos y adverbios.

Apliquémoslo a dos unidades léxicas: prisa y águila.

Si entendemos prisa como palabra explicativa (predicativa) en un enunciado como:

- Tartamudeaba y no se le entendía.

- [Es que] tenía prisa.

es porque el significado de 'tener prisa' reúne las condiciones necesarias para dar razón de la descripción que encierra -Tartamudeaba y no se le entendía.

32 Estos conceptos son paralelos a los aplicados para los tipos de definición por extensión (estación, cada uno de los periodos conocidos como primavera, verano, otoño, invierno) o por intensión (estación, periodo en que la tierra gira entre un equinoccio y un solsticio o entre un solsticio y un equinoccio), pero Moravsky los conciben como dos diferentes aspectos del significado de las unidades léxicas, entendido este como 'conjunto de condiciones para su uso'. 
Por el contrario el grado de prisa es una extensión variable que depende del contexto en que estos enunciados tuvieran su realización, no está socializado y su designación puede prestarse a confusión:

- Estuvo con ello media hora

- [Es que] tenía prisa.

- ¿Y a eso llamas tú tener prisa?

La 'prisa' de una tortuga parece que presenta otra extensión que la de una ardilla, pero no está socializada. Las extensiones del léxico, señala Moravcsik, están normalmente fijadas convencionalmente en la comunidad lingüística y varían en función del referente; también cambian diatópica, diastrática y diacrónicamente con mucha facilidad, es decir, se muestran como variaciones de una misma intensión.

El concepto de intensión, por el contrario, permite explicar el uso de las unidades léxicas en un sentido más creativo. Sería el caso de explicar enunciados como Es un águila de los negocios a través de la pregunta «¿Por qué le llamas águila?»; y de la contestación: Porque ve pronto el negocio posible y con viveza ataca o lo realiza. Este tipo de contexto explicativo (escondido bajo águila) dice mucho sobre el significado de las palabras, apunta a su intensión, se observa al sustantivo convertido en predicado, lo que le hace ser predicativo (intensión) y no sólo designativo (extensión).

Estos dos aspectos del significado léxico, entendido este como 'condiciones de uso de una unidad léxica', coinciden con la distinción de Lakoff y Johnson 1980 entre dos tipos de expresiones lingüísticas: las expresiones referenciales, que designan entidades (nombres propios y SN determinados): la torre Eiffel, mi bolso; y los predicados (como verbos y adjetivos), que designan propiedades: alto, más alto que, sobresalir. La novedad de Moravcsik es unirlas en el significado de los sustantivos, es más, de todas las palabras que él llama descriptivas (sustantivos, adjetivos, verbos y adverbios).

En la polisemia léxica hay un fenómeno, señalado en la Semántica pero no suficientemente analizado en Lexicografía, de traspaso de expresiones con extensiones físicas a expresiones sin ese tipo de extensión, llamémoslo conceptual; por ejemplo, altura de una torre o altura de miras en un proyecto. Este paso responde al concepto de cambio de dominio de la lingüística cognitiva con el que opera Lakoff para tratar las metáforas y que es interesante también para tratar la polisemia.

Lakoff concibe la metaforización como una superposición entre dos esquemas cognitivos. Esta superposición requiere un dominio de partida y un dominio de llegada; el dominio de partida posiblemente esté estructurado en un modelo proposicional o de imagen esquemática que encuentre correspondencia con otro en el dominio de llegada. El punto de partida y el de llegada están representados estructuralmente por esquemas contenedores y la superposición por un esquema de punto de partida-camino-meta. La llegada a la meta se corresponde con el cambio de dominio, en palabras de Lakoff 'cambio de contenedor' (Lakoff y Johnson 1980: 56-69).

\section{Cierre}

Nos parece que significado nuclear, extensión e intensión y cambio de dominio son los requisitos que hoy la lingüística ofrece para tratar la polisemia y para establecer rela- 
ciones semánticas coherentes dentro de un artículo lexicográfico. Repasemos un nuevo ejemplo.

En una voz como carnaza se reconocen hoy fácilmente varias acepciones extraídas de los diccionarios: 'cebo de carne usado para pescar o cazar', 'carne en abundancia', 'cosa que se emplea como atracción fácil', 'víctima inocente que carga sobre sí un daño que incumbe a otro' y 'suceso o información que despierta escándalo' ${ }^{33}$ La intensión se encuentra repartida en varias de las acepciones transcritas; si históricamente la segunda acepción de las transcritas ('carne en abundancia') fuera la considerada nuclear, le faltaría el matiz de 'atracción' que se expresa en las definiciones recogidas por usado para pescar o cazar, atracción, carga sobre sí o despertar escándalo. Si la primera acepción registrada fuera, como consignan los DRAE1992 y 2001, 'cara de las pieles que ha estado en contacto con la carne y opuesta a la flor de las mismas', no parecería tener en el estado actual de la lengua, relación semántica con las otras acepciones; pues solamente añadiéndole un factor funcional, 'y que se usa como cebo', podría coincidir con la intensión común a las otras acepciones. ${ }^{34} \mathrm{El}$ hecho de que los sentidos de "cebo o atracción' aparezcan matizados bajo expresiones diferentes en muchas de las acepciones de carnaza y, por el contrario, el que carnaza presente diversas extensiones conocidas y documentadas se contrapone patentemente con la primera acepción de esta palabra entre el DRAE y en los llamados «otros» diccionarios, ${ }^{35}$ que, en bloque, no consignan esta acepción a día de hoy.

Estos ejemplos permiten ver que el significado nuclear, a partir del cual es más fácil entender las otras acepciones, tendría que apuntar a la intensión, tendría que dejar entrever relaciones con las otras acepciones. El reconocimiento y fijación de extensiones, por el contrario, es un proceso social de la lengua que los diccionarios documentan entre las diferentes acepciones de los artículos polisémicos, cuando les dan cabida.

Podríamos aventurar que lo común a varias acepciones de un mismo lema apuntaría a una única intensión, la de la acepción en este significado nuclear. Carnaza no queda representada en su intensión hoy como 'cara de las pieles que ha estado en contacto con la carne y opuesta a la flor de las mismas', que es el antecedente histórico de la intensión actual, y que hoy es sólo un dato histórico que no sirve de nexo para trabar las otras acepciones de los diccionarios actuales. Sin embargo, 'cebo de carne usado para pescar o cazar' atrae sobre sí las otras acepciones, salvo la definición 'morfológica derivativa' apoyada en el sufijo aumentativo y despectivo -aza 'carne en abundancia', puro metalenguaje del capítulo gramatical de la derivación. ${ }^{36}$

En la acepción considerada nuclear se encuentran un género común, 'cebo', que es un tipo de alimentos para animales, y la primera diferencia específica, 'de carne', que precisa el tipo de cebo e

33 «carnaza. f. Cara de las pieles que ha estado en contacto con la carne y opuesta a la flor.||2. f. carnada (II cebo).||3. f. coloq. En una persona, abundancia de carnes. \|4. f. despect. Víctima inocente, que carga sobre sí el riesgo o el daño que incumbe a otro. Servir alguien de carnaza. Echar a alguien de carnaza» (DRAE-2001, s. v.).

34 Los últimos diccionarios no consignan la primera en el DRAE-2001: "Cara de las pieles que ha estado en contacto con la carne y opuesta a la flor de las mismas».

35 Pueden ser ejemplo de otros diccionarios actuales, DEUM, DEA, Lema, GDUEA. La denominación de «otros» es de Francisco Rico en el prólogo al GDLE Larousse 1996.

36 Hoy, que en el DRAE-2001 se han suprimido las primeras acepciones morfológicas del tipo «Participio de pasado del verbo...» en tanto que acepciones diferentes de las segundas en que la unidad léxica definida es un adjetivo, estas acepciones con definición circunscrita al sufijo apreciativo deberían desaparecer (o bien, generalizarse a todos los casos). 
incide en lo constitutivo de este cebo, frente a cebo de origen vegetal. Pero los lexicógrafos han considerado útil, en la parte especificativa de la definición, un segundo rasgo: su función, su uso; que se expresa en 'usado para pescar o cazar', que a su vez permite 'entender' las otras acepciones.

Las diferentes acepciones recogidas de carnaza varían en cuanto al género común:

cosa: género subespecificado

víctima inocente: género que marca el cambio de dominio y que recupera tanto el significado pasivo, que la comida 'ofrecida' tiene en general, como el segundo rasgo específico, 'de carne', el uso de la carne animal en los sacrificios

suceso, noticia o información: género que marca el cambio de dominio, metaforizado como alimento ofrecido a la curiosidad humana

Pero coinciden bastante en las diferencias específicas: 'que se emplea como atracción fácil', 'que carga sobre sí un daño que incumbe a otro', 'que despierta escándalo'; que coinciden todas en la utilización de 'atracción' (funcionalidad): expresada bien de una forma directa en 'se emplea como atracción'; bien de una forma indirecta en 'que carga sobre sí un daño que incumbe a otro' aplicado a una 'víctima' que es ofrecida, no que se ofrece voluntariamente; y finalmente un matiz contrario a este pasivo, un matiz capaz de poner en marcha la atracción, algo 'que despierta escándalo por sí mismo'.

Estas definiciones muestran el significado nuclear que recoge la definición de la que se ha partido: 'cebo de carne usado para pescar o cazar', 'cebo', 'carne', la forma pasiva 'usado, a' y la función 'para pescar o cazar' son datos semánticos que están de alguna manera activados con más o menos relieve o bien desactivados en diferente grado, en las definiciones de las diferentes extensiones reconocidas hoy como actuales en el español. El mayor o menor relieve que toman estos elementos nucleares, que pertenecen a la intensión, y a la que el lexicógrafo debería llegar, explica la redacción de la definición con alguna expresión como 'cosa' ${ }^{37}$ (Moravcsik 2001) o con un cambio de dominio, víctima, suceso información, etc.

La limitación de la 'atracción' a las áreas de 'la información escandalosa', del 'ofrecimiento para ser destrozado’ y de 'víctima en un sacrificio', son las fijaciones socializadas de diferentes extensiones, que los diccionarios reconocen de manera más o menos coincidente.

Bajo la concepción teórica de Moravcsik, y para la cuestión que nos interesa, la polisemia léxica y su reflejo en los diccionarios pueden ser tratados desde estos tres ángulos: a) desde las extensiones semánticas socializadas (prisa no genera y águila y carnaza sí); b) desde la intensión semántica que apunta al significado nuclear sobre el que se organizan las otras acepciones (primera acepción actual de carnaza, aparente monosemia de prisa), lo que ayudará a seleccionar finalmente el tercero; c) desde los cambios de dominio o uso intencional, y por tanto explicativo, de la unidad léxica que, partiendo del significado nuclear, se apoye en las cualidades que aparecen en la diferencia específica, es decir, en sus 'propiedades' (Lakoff y Johnson 1980) (casos de águila y carnaza).

37 El DUE utiliza a menudo para estos géneros comunes, la expresión indefinida 'lo que', disponible siempre en cualquier contexto y reconocedora de que la extensión, a la que el género común tiende a apuntar, no está suficientemente fijada; es una subespecificación. En el caso de carnaza $D U E-1998$ lo define como «Suceso, noticia, etc., generalmente de carácter cruel o violento, que alimenta sentimientos malsanos», acepción no contemplada en DUE-1967. El DVUA define carnaza como neologismo, «Lo que se emplea como elemento atractivo». 
El recorrido hecho nos permite concluir que los lexicógrafos, se encuentran ante una doble metodología para resolver la polisemia léxica en el momento de la redacción de un artículo de diccionario general monolingüe: a) definir sobre usos documentados (citas, concordancias de corpus), teniendo en cuenta frecuencias de uso para descartar hapax y usos estilísticos, $\mathrm{y}$ b) considerar las posibilidades abiertas de uso creativo de la unidad descrita o representada mantenidas en potencia en los hablantes competentes. Las posibilidades de uso creativo tienen que estar en relación con los usos documentados, pero ser más abiertas (virtuales).

Como muchos lexicógrafos han expuesto, el protocolo de análisis para determinar las acepciones y las definiciones de la unidad léxica representada por el lema parte de la consideración de un número determinado de empleos documentados de esa determinada unidad entre los que se observan coincidencias y diferencias. El grado de diferencia establece la homonimia o polisemia contrastiva y tiene incidencia en el lemario y en la macroestructura del diccionario; casos del tratamiento dado tradicionalmente a real $^{1}$, real $^{2}$, real $^{3}$ y en ciertos diccionarios de hoy a orden, acción, chino.

A partir de las coincidencias o semejanzas semánticas se establece el artículo polisémico que describirá los empleos relacionados de la unidad léxica representada por el lema. Y en el artículo conviene determinar:

- la acepción tomada como significado nuclear, redactada en un proceso recurrente a las otras acepciones que necesite la unidad léxica representada por el lema; es decir, su redacción necesitará revisiones en función de la redacción del resto de acepciones, con las que ha de mostrar alguna coincidencia intensional: carnaza como 'cebo de carne para cazar o pescar'

- las acepciones que responden a variaciones extensionales, cuyos géneros comunes están en relación de hiponimia o meronimia con el presentado en la definición tenida por nuclear. Estos han de estar socializados, caso de macuto con el significado extendido de 'mochila', como significado nuclear o como acepción.

- las acepciones subespecificadas que responden a propiedades intensionales, expresadas en la redacción de la diferencia específica de la definición tenida por nuclear, y que se apoyan en que ciertos factores explicativos (qualia) se actualicen o se inhiban; el género común de la definición debe ser amplio en su extensión y permitir adaptaciones a usos variados. No siempre están socializadas y en ellas los diccionarios no coinciden tanto: caso de otras acepciones de carnaza como «lo que se emplea como atracción fácil».

- las acepciones que representan los empleos con cambios de dominio y cuya definición tiene que sopesar un nuevo género común; las diferencias específicas de la definición han de responder a propiedades intensionales y han de reflejar también el cambio de dominio: caso de águila como «Persona de mucha viveza y perspicacia» o carnaza como «suceso, noticia o información que despiertan sentimientos primarios».

Marcar en la redacción de la definición los tipos de relaciones expuestas permitiría al usuario de diccionarios comprender y, en algún caso, generar creatividad semántica, lo que ya consigue frecuentemente la lectura competente de diccionarios monolingües, aunque este objetivo no haya sido tenido en cuenta en el proyecto de un diccionario. Por eso mismo también, lo expuesto aquí parece una base atendible para diccionarios de aprendizaje, que siempre exigen más explicitación y mayor coherencia en la información ofrecida, al no contar sus usuarios con toda la disponibilidad del hablante competente. 


\section{REFERENCIAS BIBLIOGRÁFICAS}

APresJan, Juri D. (1973): «Regular Polysemy», Linguistics, 142, pp. 5-32.

Battaner, Paz y Javier Lahuerta (2002): «Nombres femeninos en el diccionario: problemas de lematización», en J. I. Pérez Pascual y M. Campos Souto, eds., Cuestiones de Lexicografía, Lugo, Tris Tram, pp. 53-62.

Battaner, Paz y Sergi Torner (2007): «Designación y predicación en las definiciones lexicográficas», en M. Campos Souto, E. Conde Noguerol, J. I. Pérez Pascual y J.-A. Porto Dapena, eds., Reflexiones sobre el diccionario, A Coruña, Universidade da Coruña, pp. 151-164.

BosQue, Ignacio (1982): «Más allá de la lexicalización», BRAE, LXII, pp. 103-158.

CAsAs Gómez, M. y M. D. MuÑoz NúÑEz (1992): «La polisemia y la homonimia en el marco de las relaciones léxicas», en G. Wotjak, ed., Estudios de lexicología y metalexicografía del español, Tubinga, Max Niemeyer, pp. 134-158.

CASARES, Julio (1992 [1951]³): Introducción a la Lexicografía Moderna, Madrid, CSIC.

COSERIU, Eugenio (1978²): Gramática, semántica, universales: estudios de lingüística funcional, Madrid, Gredos.

CRuse, Alan (1986): Lexical Semantics, Cambridge, Cambridge University Press.

(1992): «Monosmy vs. polysemy. Review article on Ruhl (1989)», Linguistics, 30, pp. 577-599.

(2000): Meaning in Language, An Introduction to Semantics and Pragmatics, Oxford, Oxford University Press.

DeCesaris, Janet y Paz Battaner (2005): «Una cuestión de semántica léxica en los diccionarios del español bajo las fórmulas por extensión y en especial», en G. Wotjak y J. Cuartero Otal, eds., Entre semántica léxica, teoría del léxico y sintaxis, Frankfurt, Peter Lang, pp. 133-150.

GutiéRrez OrdóÑEz, Salvador (1989): Introducción a la Semántica Funcional, Madrid, Síntesis.

Evens, Martha W., ed., (1988): Relational models of the lexicon representing knowledge in semantic networks, Nueva York, Cambridge University Press.

Hoyos, J. C. de (1999-2000): «La marca de transición semántica: sentido figurado», Revista de Lexicografia, VI, pp. 73-105.

KilgarrifF, Adam (1992): Polysemy, Brighton, University of Sussex.

KleIBer, Georges (1999): Problèmes de sémantique: la polysémie en questions, Villeneuve d'Ascq, Presses Universitaires du Septentrion.

LAKoff, G. y M. Johnson (1980): Metaphors We Live By, Chicago, University of Chicago Press.

LARA, Luis Fernando (1997): Teoría del diccionario monolingüe, México, El Colegio de México.

MAKKAI, Adam (1972): Idiom structure in English, La Haya, Mouton.

MeER, G. van der (2000): «Core, subsense and the New Oxford Dictionary of English (NODE). On how meanings hang together and not separately», en Proceedings of the Ninth Euralex International Congress, EURALEX 2000, Stuttgart, Germany, Stuttgart, Universidad de Stuttgart, II, pp. 419-432.

Moliner, María (1966): «Presentación», en Diccionario de uso del español, Madrid, Gredos, pp. II-XLV.

Moravcsik, Julius M. (1990): Thought and Language, Londres-Nueva York, Rouletdge.

(2001): «Metaphor, Creative Understanding, and the Generative Lexicon», en P. Bouillon e I. Busa, eds., The Language of Word Meaning, Cambridge, Cambridge University Press, pp. 247-261. 
Muñoz NúÑEz, M. Dolores (1999): La polisemia léxica, Cádiz, Universidad de Cádiz.

NUNBERG, Geoffrey y Annie ZAENEN (1997): «La polysémie systematique dans la description lexicale», trad. de «Systematic Polysemy in Lexicology and Lexicography» (1992), Langue Française, 113, pp. $12-23$

Porto Dapena, José-Álvaro (2002): Manual de técnica lexicográfica, Madrid, Arco/Libros.

PusteJovsky, James (1995): The Generative Lexicon, Cambridge (Mass.), MIT Press.

y Branimir Boguraev, eds. (1996): Lexical semantics, the problem of polysemy, Oxford, Clarendon Press.

Putnam, Hilary (1975): Mind, language, and reality, Cambridge, Cambridge University Press

Ravin, Yael y Claudia LEACOCK, (2000): Polysemy, Theoretical and Computational Approaches, Nueva York, O.U.P.

Rico, Francisco (1996): «El Diccionario de la Academia y “los otros”» en Gran Diccionario de la Lengua Española, Barcelona, Larousse (sin paginar).

SÁncheZ, Aquilino, dir. (2001): «Introducción» en Gran Diccionario de Uso del Español Actual, Madrid, Sociedad General Española de Librería, pp. 7-14.

SinclaIR, John (1987): Collins COBUILD English Dictionary, Londres, Harper Collins.

Victorri, Bernard (1996): La Polysémie, construction dynamique du sens, con la colaboración de Catherine Fuchs, París, Hermès.

Vivanco Cervero, Verónica (2003) Homonimia y polisemia, teoría semántica y aplicación lexicográfica, Buenos Aires, Ediciones del Sur.

Diccionarios citados:

Clave: C. Maldonado GonzÁlez, dir. (1997): Clave, diccionario de uso del español actual, prólogo de Gabriel García Márquez, Madrid, SM.

COBUILD: John SinClair, ed. (1987): Collins Cobuild English Dictionary, Londres, Harper Collins.

DEA: M. Januel Seco, dir., O. Andrés y G. RAmos (1999): Diccionario del español actual, Madrid, Aguilar, 2 vols.

DEUM: Luis Fernando LARA, dir. (1996): Diccionario del Español Usual en México, México, El Colegio de México-Centro de Estudios Lingüísticos.

DRAE-1992: Real ACAdEMIa Española (199221): Diccionario de la Lengua Española, Madrid, Espasa.

DRAE-2001: ReAl ACAdEMIA Española (200122): Diccionario de la Lengua Española, Madrid, Espasa.

DUE-1967: M. Moliner (1967): Diccionario de uso del español, Madrid, Gredos.

DUE-1998: M. Moliner (1998²): Diccionario de uso del español, Madrid, Gredos.

DVUA: M. Januel Alvar EzQuerra, dir. (1994), Diccionario de voces de uso actual, Madrid, Arco/Libros

GDLE Larousse: M. Antonia MARTí, coord. (1996), Gran diccionario de la Lengua Española, Barcelona, Larousse-Planeta.

GDUEA: Aquilino SÁNCHEZ, dir. (2001): Gran diccionario de uso del español actual, Madrid, SGEL.

Lema: Paz Battaner, dir. (2001): Lema, diccionario de la lengua española, Vox, Barcelona, Spes Editorial. 
Lexis: Jean DuboIs, dir. (1975): Lexis, dictionnaire de la langue française, París, Larousse.

OED: J. A. SIMPSON y E. S. C. WeINER, eds. $\left(1991^{2}\right)$ : The Oxford English dictionary, Oxford, Clarendon - Oxford University Press [consulta on line 2001].

Redes: Ignacio Bosque, dir. (2004): Redes, Diccionario combinatorio del español contemporáneo, Madrid, SM.

TLF: Paul IMBS y Bernard QuemadA, dirs. (1971-1994): Trésor de la langue française, dictionnaire de la langue du XIXe et XXe siècle, París, CNRS-Gallimard [ed. electrónica en CD Rom: Trésor de la langue française informatisé, París, CNRS Éditions, 2004]. 